\title{
List sizes and use of time in general practice
}

\author{
J R BUTLER, M W CALNAN
}

\begin{abstract}
The claim that list sizes in general practice should continue to fall towards a national average of 1700 patients rests heavily on the assumption that the extra time available to doctors would be used mainly for longer consultations, resulting in better standards of care. Evidence suggests, however, that the time is more likely to be used to increase rates of consultation in surgeries and home visits and to reduce the length of the working week. A national, random sample of 2104 principals in general practice in England and Wales were questioned about their allocation and use of time. The response rate was $67 \%$, and no large biases in response were detected. The smaller their personal list size the less time general practitioners spent on all aspects of their work and the higher their rates of consultation and home visiting.

The effects of further reductions in list sizes would be haphazard, being differentially distributed across the range of list sizes. Longer consultations would probably result, but most of the extra time would probably be used in higher rates of consultation in surgeries and home visits and some would be taken as free time.
\end{abstract}

\section{Introduction}

For several years the policy of the General Medical Services Committee has been that list sizes in general practice should fall to a target national average of 1700 . This is usually justified on the grounds that smaller lists produce higher standards of care. ${ }^{1}$ The key factor that is believed to mediate the relation between list sizes and standards of care is time: if general practitioners acquire smaller lists, the argument runs, they will have time to enhance the standard of care in their practices. ${ }^{2}$

Longer consultations, which should be possible with smaller lists, are often assumed to be important means of raising standards:

Health Services Research Unit, University of Kent, Canterbury, Kent CT2 7NF

J R BUTLER, MA, PHD, professor of health services studies $M$ W CALNAN, MSC, PHD, senior research fellow

Correspondence to: Professor Butler.
"It is shortage of consultation time that is the greatest single obstacle to improvement and extension of primary health care services by general practitioners." 3 This is an incomplete argument for it fails to specify exactly how longer consultations would generate more or better care, but it has support: longer consultations have been associated with lower rates of prescribing, ${ }^{4}$ lower rates of follow up consultation, ${ }^{5}$ and greater patient satisfaction, ${ }^{6}$ all of which may raise standards. Longer consultations also lead to a more thorough exploration of patients' problems and to more opportunistic screening. ${ }^{7}$

Further reductions in the size of general practitioners' lists may not, however, lead automatically to more or better care. General practitioners might respond to smaller lists not by reinvesting the extra time at their disposal in longer consultations but by using it to increase their rates of consultation in the surgery and home visiting, expand the range of services they offer (such as child health surveillance and well men clinics), increase their private work, become more active in training or research, or, simply, reduce the number of hours worked each week. Some of these alternative uses of time may lead to better care, but others plainly do not.

In his review of published studies up to 1980 Butler found little evidence of any systematic variation with list size in the total number of hours spent each week by general practitioners in caring for patients. ${ }^{8}$ The extra time available to doctors with smaller lists was much less likely to be spent on longer consultations than on higher rates of consultation in the surgery and home visiting. Later work, however, pointed towards a different conclusion. In their study of 199 general practitioners in inner and outer Manchester Wilkin and Metcalfe found a strong positive correlation between list size and the aggregate amount of time spent each week on consultations and home visits. ${ }^{9}$ This finding, which was subsequently corroborated by a national survey of general practitioners' workloads conducted jointly by the General Medical Services Committee and the Department of Health and Social Security, ${ }^{10}$ suggests that at least part of the extra time available to doctors with smaller lists is not reinvested in the care of patients but is spent on other activities or even taken as free time. Wilkin and Metcalfe's study' did, however, support the earlier work reviewed by Butler ${ }^{8}$ in showing that there is no more than a slight relation between list size and length of consultation and an inverse association between list size and the rate of consultation. Thus it may be unrealistic to expect general practitioners to respond automatically to smaller lists by increasing their length of consultations. 
TABLE I-Respondents' estimates of time spent each week on general medical services activities. Values are numbers of general practitioners (percentages)

\begin{tabular}{|c|c|c|c|c|c|c|c|c|}
\hline & \multicolumn{7}{|c|}{ No of hours each week } & \multirow{2}{*}{$\begin{array}{c}\text { Mean } \\
\text { No of hours }\end{array}$} \\
\hline & $\leqslant 5$ & -10 & -15 & -20 & -25 & -30 & $>30$ & \\
\hline $\begin{array}{l}\text { Surgery consultations }(n=1390) \\
\text { Home visits (including travelling) }(n=1378) \\
\text { Practice administration }(n=1410) \\
\text { Reading, research, training courses }(n=1409) \\
\text { Other }(n=1411)\end{array}$ & $\begin{array}{r}9(1) \\
259(20) \\
1191(85) \\
1223(87) \\
1234(88)\end{array}$ & $\begin{array}{l}43(3) \\
616(45) \\
181(13) \\
154(11) \\
152(10)\end{array}$ & $\begin{array}{l}267(19) \\
299(22) \\
30(2) \\
22(2) \\
16(1)\end{array}$ & $\begin{array}{l}564(41) \\
140(10) \\
4(<1) \\
8(1) \\
9(1)\end{array}$ & $\begin{array}{l}308(22) \\
37(3) \\
4(<1) \\
1(<1)\end{array}$ & $\begin{array}{l}136(10) \\
20(1) \\
1(<1)\end{array}$ & $\begin{array}{r}63(5) \\
7(1)\end{array}$ & $\begin{array}{r}20 \cdot 0 \\
10 \cdot 5 \\
3 \cdot 2 \\
2 \cdot 9 \\
2 \cdot 2\end{array}$ \\
\hline All general medical services activities & & & & & & & & $38 \cdot 8$ \\
\hline
\end{tabular}

TABLE II-Respondents' estimates of time spent each week on non-general medical services activities. Values are numbers of general practitioners (percentages)

\begin{tabular}{|c|c|c|c|c|c|c|c|}
\hline & \multicolumn{6}{|c|}{ No of hours each week } & \multirow{2}{*}{$\begin{array}{c}\text { Mean } \\
\text { No of hours }\end{array}$} \\
\hline & None & $\leqslant 1$ & -2 & -3 & -4 & $>4$ & \\
\hline $\begin{array}{l}\text { Private practice }(n=1413) \\
\text { Hospital appointments }(n=1399) \\
\text { Insurance work }(n=1377) \\
\text { Clinics }(n=1406) \\
\text { Police and industrial work }(n=1397) \\
\text { Committee work }(n=1391) \\
\text { Teaching }(n=1385) \\
\text { Other }(n=1394)\end{array}$ & $\begin{array}{r}1178(83) \\
985(70) \\
656(48) \\
1076(77) \\
1168(84) \\
1080(78) \\
1260(91) \\
1203(86)\end{array}$ & $\begin{array}{l}139(10) \\
30(2) \\
477(34) \\
97(6) \\
89(6) \\
169(12) \\
68(5) \\
36(3)\end{array}$ & $\begin{array}{l}44(3) \\
52(4) \\
172(13) \\
130(10) \\
51(4) \\
75(5) \\
23(2) \\
41(3)\end{array}$ & $\begin{array}{l}16(1) \\
75(4) \\
51(4) \\
42(3) \\
22(1) \\
32(2) \\
16(1) \\
34(2)\end{array}$ & $\begin{array}{l}7(<1) \\
81(6) \\
16(2) \\
29(2) \\
19(2) \\
13(1) \\
7(1) \\
19(1)\end{array}$ & $\begin{array}{l}29(2) \\
176(13) \\
5(<1) \\
32(2) \\
48(3) \\
22(2) \\
11(1) \\
61(4)\end{array}$ & $\begin{array}{l}0.4 \\
1.4 \\
0.7 \\
0.6 \\
0.5 \\
0.4 \\
0.2 \\
0.5\end{array}$ \\
\hline All non-general medical services & & & & & & & $4 \cdot 7$ \\
\hline
\end{tabular}

TABLE III-Respondents' estimates of mean time (hours) spent each week on all activities by personal list size

\begin{tabular}{|c|c|c|c|c|c|c|}
\hline & \multicolumn{5}{|c|}{ Personal list size } & \multirow{2}{*}{$\begin{array}{l}\text { All } \\
\text { respondents }\end{array}$} \\
\hline & $<1500$ & -1999 & -2499 & -2999 & $\geqslant 3000$ & \\
\hline Surgery consultations & $15 \cdot 8$ & $18 \cdot 7$ & $19 \cdot 8$ & $20 \cdot 8$ & $22 \cdot 1$ & $20 \cdot 0$ \\
\hline Home visits (including travelling) & 8.5 & $9 \cdot 3$ & $10 \cdot 6$ & $11 \cdot 3$ & $10 \cdot 8$ & 10.5 \\
\hline Practice administration & 3.6 & $3 \cdot 4$ & $3 \cdot 1$ & $3 \cdot 1$ & $3 \cdot 1$ & $3 \cdot 2$ \\
\hline Reading, research, training courses & $3 \cdot 2$ & $2 \cdot 7$ & $3 \cdot 0$ & $2 \cdot 7$ & $2 \cdot 8$ & $2 \cdot 9$ \\
\hline Private practice & 0.6 & 0.4 & 0.4 & 0.2 & 0.5 & $0 \cdot 4$ \\
\hline Hospital appointments & $1 \cdot 2$ & $1 \cdot 4$ & $1 \cdot 4$ & 1.6 & $1 \cdot 2$ & $1 \cdot 4$ \\
\hline Insurance work & 0.4 & 0.6 & 0.7 & 0.8 & 0.9 & 0.7 \\
\hline Clinics & 0.7 & 0.5 & 0.5 & 0.6 & 0.6 & 0.6 \\
\hline Police and industrial work & 0.4 & 0.6 & 0.4 & 0.5 & 0.5 & 0.5 \\
\hline Committee work & 0.3 & 0.4 & 0.4 & 0.4 & 0.6 & 0.4 \\
\hline Teaching & 0.6 & 0.2 & 0.2 & 0.2 & 0.1 & 0.2 \\
\hline \multicolumn{7}{|l|}{ Other: } \\
\hline General medical services & 1.6 & $2 \cdot 1$ & 0.2 & $2 \cdot 3$ & $2 \cdot 4$ & $2 \cdot 2$ \\
\hline Non-general medical services & 0.4 & 0.5 & 0.6 & 0.5 & 0.5 & 0.5 \\
\hline All activities & $37 \cdot 3$ & $40 \cdot 8$ & $43 \cdot 3$ & $45 \cdot 0$ & $46 \cdot 1$ & $43 \cdot 5$ \\
\hline
\end{tabular}

There are, however, deficiencies in previous studies: they were usually limited geographically, were often confined to self selected practitioners, sometimes had low rates of response, and did not usually measure the allocation of time among all the components of the working week. In our study we surmounted these deficiencies by exploring some aspects of the putative relation between list sizes and standards of care.

\section{Methods}

The study was a postal survey of a non-stratified sample of unrestricted principals in England and Wales drawn at random from the April 1984 quarterly file of the Doctor Index. The addresses of the 2104 doctors selected were obtained from the Medical Directory, the Medical Register, and telephone calls to family practitioner committees. The first mailing was sent in October 1984, and four follow up mailings were used. Altogether 1419 doctors replied, giving a response rate of $67 \%$.

Seven characteristics were obtained for most of the non-responders as well as the responders: year and place of qualification, sex, whether they were members of the Royal College of General Practitioners, personal list size, average list size in the practice, and regional location. Personal list size and regional location showed no significant differences between responders and non-responders; the five other characteristics showed significant differences at the 0.01 or 0.05 levels in a $\chi^{2}$ test, although the percentage variations were quite small. There was an appreciably lower rate of response from doctors who had qualified before 1940 (and to a less extent 1950) than from younger doctors, and those in practices that had the largest and smallest average list sizes were less likely to respond than those from practices with list sizes in the middle of the range. Overall, there did not seem to have been any serious bias in response. The personal lists of singlehanded practitioners and of those in group practices operating a personal list system were taken as being the numbers of National Health Service patients registered with the doctor. The lists of doctors in group practices operating a "free flow" system were taken as being their replies to the question: "If you were to change to a personal list of patients what size would it have to be to give you the same workload as you now have?" With this pluralistic method the range in reported personal list sizes was $120-4600$, the mean number 2308 , and median number 2300 .

\section{Results}

\section{BELIEFS ABOUT LIST SIZES, TIME, AND STANDARDS}

The respondents' answers generally endorsed the conventional view of an association between list sizes and standards of care. Altogether 1063 of the 1419 respondents said that they would ideally have liked a smaller list of patients, and 872 of these expected that they would spend more time, on average, on each consultation if they acquired a list of their ideal size. Their mean ideal booking interval was $9 \cdot 8$ minutes compared with a mean reported booking interval of 6.9 minutes. Moreover, 453 respondents thought that at least half their consultations in the surgery would result in a better outcome for patients if more time was available, and a further 285 rated between a quarter and a half of their surgery consultations in this way. But how were the respondents with differing list sizes actually using their time? 


\section{USE OF TIME}

Several methods are available for measuring the allocation of time, including direct observation, activity sampling, diary records, and personal estimations. We asked respondents to estimate the number of hours that they had spent in the previous week on a variety of listed activities inside and outside their practices. The results from this method were similar to those recently derived from other methods-for example, the doctors reported spending a mean of 38.8 hours a week on general medical services activities (excluding time on call), of which 20.0 hours were spent on surgery consultations; the survey by the General Medical Services Committee and Department of Health and Social Security, which entailed doctors keeping detailed diaries for a week, yielded corresponding figures of 38.2 and $17 \cdot 9$ hours. ${ }^{10}$ These comparisons suggest that the results presented below are acceptably close to the "true" national picture.

Tables I and II show the distribution of the respondents' estimates of the time spent each week on general medical services and non-general medical services activities, respectively, and table III shows the mean estimates for doctors according to size of list. There were appreciable variations among respondents with different list sizes. With increasing list sizes doctors spent more time, on average, on general medical services activities; those with lists of 3000 and more were spending an average of 6.3 hours a week more on surgery consultations than those with lists of less than 1500 and $2 \cdot 3$ hours a week more on home visits. Moreover, the doctors with smaller lists were not spending the extra time on non-general medical services work as the aggregate amount of time spent on these activities also showed a slight positive association with list size. In short, the smaller the list sizes of doctors the less time they seemed to spend on all aspects of their work and hence the more time they seemed to have free. Part of the time may, however, have been reinvested in longer consultations and higher rates of consultation, and only part of it taken as free time. To test this possibility we calculated the rates of consultation and lengths of consultation according to list size.

\section{CONSULTATION RATES AND LENGTHS}

Respondents were asked to record the total numbers of patients they had seen in general surgeries and clinics during the preceding week and also the total number of home visits they had made. The reported numbers of consultations and visits were consistent with those found in other surveys using different methods-for example, the mean reported number of patient contacts each week was 185 compared with 174 in the survey by the General Medical Services Committee and Depar'ment of Health and Social Security. ${ }^{10} \mathrm{By}$ multiplying the weekly number of consultations in the surgery and home visits by 52 and relating them to the respondents' list sizes we estimated annual rates of consultation and home visiting to be 3.7 and 0.6 , respectively, for the total sample. The estimated rate of consultations in the surgery (3.7) was consistent with national figures derived in different ways from other sources: the 1981 national morbidity survey found mean annual surgery consultation rates of 2.71 and 4.02 for men and women, respectively, ${ }^{11}$ and the 1983 general household survey reported corresponding rates of 2.5 and $4 \cdot 9 .{ }^{12}$ Our estimated rate for home visiting $(0.6)$ was a little higher than that in the 1981 national morbidity survey $(0.3$ and 0.5 for men and women, respectively). ${ }^{11}$

Tables IV and $\mathrm{V}$ show the reported numbers, and corresponding estimated rates, of consultation in the surgery and home visits, respectively, according to list size. These results were consistent with the conclusion of both the Manchester study and the survey by the General Medical Services Committee and Department of Health and Social Security, which was that, although the numbers of consultations and home visits are positively associated with list size, the estimated rates are inversely associated-that is, the smaller the general practitioner's list the higher the rates of consultation and home visiting. Part of the extra time available to general practitioners with smaller lists was thus being reinvested in their practice work in the form of increased rates of contact with patients and a part of it was being taken as free time.

TABLE IV-Mean number of patients seen each week in surgeries and clinics and estimated annual consultation rate by personal list size

\begin{tabular}{lccc}
\hline Personal list size & $\begin{array}{c}\text { Mean No of patients } \\
\text { seen weekly }\end{array}$ & $\begin{array}{c}\text { Annual } \\
\text { consultation rate }\end{array}$ & $\begin{array}{c}\text { No of } \\
\text { respondents }\end{array}$ \\
\hline$<1500$ & 106 & $5 \cdot 3$ & 90 \\
-1999 & 129 & $4 \cdot 0$ & 195 \\
-2499 & 154 & $3 \cdot 7$ & 471 \\
-2999 & 180 & $3 \cdot 6$ & 327 \\
$\geqslant 3000$ & 208 & $3 \cdot 3$ & 224 \\
\hline All respondents & 163 & $3 \cdot 7$ & 1307 \\
\hline
\end{tabular}

TABLE V-Mean number of home visits each week and estimated annual rate of home visiting by personal list size

\begin{tabular}{lccc}
\hline Personal list size & $\begin{array}{c}\text { Mean No of home } \\
\text { visits weekly }\end{array}$ & $\begin{array}{c}\text { Annual rate of home } \\
\text { visiting }\end{array}$ & $\begin{array}{c}\text { No of } \\
\text { respondents }\end{array}$ \\
\hline$<1500$ & 16 & 0.8 & 82 \\
-1999 & 20 & 0.6 & 190 \\
-2499 & 24 & 0.6 & 439 \\
-2999 & 27 & 0.5 & 307 \\
$\geqslant 3000$ & 30 & 0.5 & 217 \\
\hline All respondents & 25 & 0.6 & 1235 \\
\hline
\end{tabular}

TABLE VI-Mean reported booking interval by personal list size

\begin{tabular}{lcc}
\hline Personal list size & $\begin{array}{c}\text { Mean reported booking } \\
\text { interval (minutes) }\end{array}$ & $\begin{array}{c}\text { No of } \\
\text { respondents }\end{array}$ \\
\hline$<1500$ & $8 \cdot 2$ & 80 \\
-1999 & $7 \cdot 3$ & 168 \\
-2499 & $7 \cdot 1$ & 432 \\
-2999 & $6 \cdot 6$ & 293 \\
$\geqslant 3000$ & $6 \cdot 1$ & 200 \\
\hline All respondents & 6.9 & 1173 \\
\hline
\end{tabular}

TABLE VII-Time saved by respondents in each band of list sizes (relative to next bigger band) and uses to which it was put

\begin{tabular}{lcccc}
\hline & \multicolumn{4}{c}{ Personal list size } \\
\cline { 2 - 5 } & $<1500$ & -1999 & -2499 & -2999 \\
\hline Total hours saved & 8.0 & 5.3 & 4.9 & 5.6 \\
Use of hours saved: & & & & \\
$\quad$ Higher consultation rates & 3.6 & 1.2 & 0.5 & 1.7 \\
Higher home visiting rates & 1.0 & 0.2 & 0.7 & 0.5 \\
Longer booking intervals & 1.2 & 0.4 & 1.3 & 1.4 \\
Other & 2.2 & 3.5 & 2.4 & 2.0 \\
\hline
\end{tabular}

The lengths of the consultations in the surgery were not measured directly, but responders who operated an appointment system $(83 \%$ (1173) of the total sample) were asked to record the booking interval they used. The mean reported interval $(6.9$ minutes) was shorter than that in both the Manchester study $(7 \cdot 4$ minutes) and the General Medical Services Committee and Department of Health and Social Security survey ${ }^{10}$ (8.3 minutes) but was consistent with intervals of other recently published studies. ${ }^{1314}$ Table VI shows an inverse association between mean booking interval and list size: doctors with lists of less than 1500 allowed, on average, over two minutes more for each patient than those with lists of 3000 and above. This means that part of the extra time available to general practitioners with smaller lists was reinvested in longer average consultations as well as in increased rates of contact with patients.

\section{USE OF TIME: AN OVERVIEW}

A rough estimate of the division of the extra time of doctors with smaller lists among consultations in the surgery, home visits, booking intervals, and free time was made by comparing the doctors in each band of list size with those in the next highest band and calculating how they would have used their time if they had actually had the same estimated consultation rate, the same estimated rate of home visiting, and the same mean booking interval as those in the next highest band. Table VII summarises the results and shows, for example, that respondents with fewer than 1500 patients on their list would have worked an average of 8.0 fewer hours a week than those in the next highest band. In fact, however, some of those 8.0 hours were actually used to sustain their higher rates of consultation and visiting; indeed, about 3.6 of the 8.0 hours were used to sustain the higher rates of consultation, 1.0 hour to sustain the higher rates of home visiting, and 1.2 hours to sustain the longer booking interval. The balance $(2 \cdot 2$ hours $)$ represents the amount of saved time that was spent on other things, and as it was apparently not reinvested in other general medical services or non-general medical services work (table III) it was presumably taken as free time.

Implicit in this form of analysis is the assumption that doctors who acquire smaller lists in the course of a reduction in list sizes will behave in the same way as doctors who currently have lists of that size. Yet such an assumption cannot be taken for granted: list size alone may not determine the allocation 
and use of time, and merely to reduce the numbers of patients on doctors' lists may not produce the expected changes in behaviour.

To test the distinctive effect of list size on such variables as length of consultations, hours worked, and rates of surgery consultation and home visiting we performed a stepwise multiple regression analysis, taking account of possible confounding and other independent variables. The dependent variables used in the analysis were the booking interval, hours a week spent on consultations and home visits, total hours a week spent on all general medical services and non-general medical services activities, and annual rates of consultation in the surgery and home visiting. The independent variables (in addition to list size) were age; sex; place of qualification; geographical location; practice size; location of health centre; trainership state; vocational training undergone; perception of workload; membership of the Royal College of General Practitioners; job satisfaction; attitudes towards deputising services; attitudes towards the effectiveness of modern medicine; and the presence of a practice nurse, district nurse, midwife, and health visitor in the primary health care team. The values for these variables and the full results of the analyses have been reported. ${ }^{15} \mathrm{O}$ the 18 independent variables used, personal list size was the most powerful predictor for each of the dependent variables. The only other independent variable explaining a fairly large part of the variance was the location of the practice, with doctors in rural locations having higher rates of home visiting than those in urban areas.

These results confirmed that personal list size was a fairly strong predictor of the way doctors use their time and construct their work, even when a wide range of other possible influences were taken into account. The overall variances explained by list size (and also by the other independent variables), however, were small, implying that other unknown but important influences are also operating.

\section{Discussion}

General practitioners have increasing': been expected in recent years to take on a variety of new responsibilities, from the surveillance of child health and prevention of arterial disease to the postoperative care of patients discharged early from hospital and the oversight of those discharged from long stay institutions into community care programmes. To cope with these added responsibilities they need additional resources, including time. The core of the case for the continuing reduction in list sizes is that general practitioners will reinvest the extra time in ways that will permit new forms of care and improvements in existing care.

The argument that a continuing reduction in list sizes is a necessary precondition for an extension of a general practitioner's responsibilities is difficult to dispute, but it is not obviously a sufficient precondition. As independent contractors general practitioners have considerable control over the content and structure of their work, and they are unlikely all to respond in predetermined ways to the opportunities provided by smaller lists. Some might wish to expand their private commitments; others to develop their interests in training, research, or management; and others to enjoy a shorter working week. In view of the costs entailed in moving towards the General Medical Services Committee's target of a national average list size of 1700 (estimated to be in excess of $£ 300$ million a year at 1982 prices $^{16}$ ) some evidence of the likely pay off would seem to be prudent.

Our results offer partial support to those who wish to see further reductions in list sizes. The proportion of time that was reinvested in higher booking intervals was quite small. The figures suggest, however, that longer consultations may be a higher priority for doctors at the upper than for those at the lower end of the range of list sizes. About a quarter of the time saved by general practitioners with lists of between 2000 and 3000 was used in this way compared with $8 \%$ and $15 \%$, respectively, in the lower two bands. The proportion of time reinvested in higher rates of consultation varied from one band of list sizes to another. It represented the largest reinvestment of time among doctors with the smallest lists and was the second largest among those with lists of 2500-2999. The proportion of time that was presumably taken as free time was quite large, accounting for between about a quarter and two thirds of the total hours saved. In all but the lowest band of list size this category represented the largest single use of time.

An increase in rates of consultation and home visiting may or may not be a valid indicator of better care. If increased rates resulted in patients whose needs were formerly unmet now gaining access to the doctor the change would unquestionably be beneficial; likewise, frequent short consultations may be good for some patients with chronic conditions or for the lonely or elderly. If, however, time was spent on unnecessary follow up consultations the result would merely be a loss of efficiency.

Our findings imply that ways may need to be found of persuading general practitioners whose lists decrease to reinvest the time saved in particular ways. A recent review of possible ways of influencing the behaviour of general practitioners concluded that financial incentives to change were much less effective than personal contact or group educational programmes. ${ }^{17}$ If this is true the government ought to be more responsive to the Royal College of General Practitioners, which is pressing for a massively increased investment in education and training, ${ }^{18}$ than to the General Medical Services Committee, which is arguing for an extension of item of service payments. ${ }^{19}$ The cost of an adequate investment in education and training, however, would be high (the figure suggested by the Royal College of General Practitioners was $£ 100$ million a year at 1986 prices); it is thus important that the expected benefits should be high enough to justify the cost of a policy of this kind.

One way forward may be a prospective study in which the lists in several practices are systematically reduced in size and the effects assessed; control practices with no such reductions would be needed. In this way several of the uncertainties discussed in this paper might be clarified. Meanwhile, the evidence from this study and the survey by the General Medical Services Committee and the Department of Health and Social Security does not suggest that merely continuing to reduce the national average list size will produce the quantity of benefits put forward by the proponents of smaller lists. As Day and Klein argued recently, "the policy debate about general practice should not take as its focus the issue of list size. Crude list size does not seem to be an appropriate instrument of policy, whether for planning or for distributing the existing number of general practitioners." 20

We are grateful to Jill Relton and Barbara Wall for their help in preparing this paper, and to John Horder, Rose Knight, David Morrell, Michael Warren, and David Wilkin for their comments on an earlier draft. The study was funded by a grant from the Department of Health and Social Security.

This paper is based on material from our forthcoming book Too Many Patients? A Study of the Economy of Time and Standards of Care in General Practice. We are grateful to Gower Publishing Company for permission to use the material here.

\section{References}

1 General Medical Services Committee. General practice: a British success. London: British Medical Association, 1983.

2 Morrell DC, Roland MO. How can good general practitioner care be achieved? Br Med $\mathcal{f}$ 1987;294:161-2.

3 Social Services Committee. First report 1986-87. Primary health care. London: HMSO, 1987

4 Murray TS, Barber JH, Hannay DR. Consulting time and prescribing rates. Update 1978;16: 969-75.

5 Hughes D. Consultation length and outcome in two group general practices. $f R$ Coll Gen Pract 1983;33:143-7.

6 Hull GM, Hull FS. Time and the general practitioner: the patient's view. $f(R$ Coll Gen Pract 1984;34:71-5.

7 Morrell DC, Evans ME, Morris RW, Roland MO. The "five minute" consultation: effect of time constraint on clinical content and patient satisfaction. BrMed f 1986;292:870-3.

8 Butler JR. How many patients? A study of list sizes in general practice. London: Bedford Square Press, 1980. (Occasional Papers in Social Administration No 64.)

9 Wilkin D, Metcalfe D. List sizes and patient contact in general medical practice. $\mathrm{Br}$ Med $J$ 1984;289:1501-5.

10 Department of Health and Social Security and the General Medical Services Committee. General medical practitioners' workload. A report prepared for the Doctors' and Dentists' Review Body 1985/86. London: DHSS, 1987.

11 Office of Population Censuses and Surveys. Third national study of morbidity statistics from general practice: 1981/2. OPCS Monitor 1986 Jan 21. (MB5 86/1.)

12 Office of Population Censuses and Surveys. General household survey 1983. London: HMSO, 1985.

13 Pringle M Robins S, Brown G. Timer: a new objective measure of consultation content and its application to computer assisted consultations. BrMed f 1986;293:20-2.

14 Wilson AD. Consultation length: general practitioners' attitudes and practice. $\mathrm{Br}$ Med 1985;290:1322-4.

15 Butler JR, Calnan MW. Too many patients? A study of the economy of time and standards of care in general practice. Aldershot: Gower Publishing (in press)

16 Anonymous. GMSC discusses reduction in average list size. $\mathrm{Br}$ Med $\mathcal{f}$ 1982;285:1675.

17 Horder J, Bosanquet N, Stocking B. Ways of influencing the behaviour of general practitioners J R Coll Gen Pract 1986;36:517-21.

18 Royal College of General Practitioners. The front line of the health service. London: RCGP, 1987. (Report from General Practice 25.)

19 General Medical Services Committee. Report to special conference of representatives of local medical committees on 13 November 1986. London: British Medical Association, 1986.

20 Day P, Klein R. General practice: a blurred snapshot. Br Med f 1987;295:253-5.

(Accepted 30 September 1987) 